\title{
El sujeto como sistema (Séptimas Conferencias Aranguren, 1998)
}

\author{
CARLOS CASTILLA DEL PINO \\ Universidad de Córdoba
}

El sujeto es un sistema de producción, reconstrucción, deconstrucción y almacenamiento de yoes con miras a la concreta actuación en un contexto determinado. Hay yoes imaginados (prolépticos), anticipados, proyectos de yoes actualizados y yoes fantaseados (y soñados). Los yoes se constituyen en módulos que el sujeto, como sis- tema, reutiliza en ulteriores contextos. El sujeto controla la actuación del yo creado para la situación, y lo modifica si su actuación no es del tipo adecuado para el logro del propósito del sujeto. El lugar del sujeto es el neocortex prefrontal; el del yo, el cuerpo y lo que el sujeto le exige hacer para la interacción real o virtual.

\section{PRELIMINAR}

Si algo queda de alguien en cada uno de nosotros, su sitio, valga la expresión, es nuestra memoria personal. Mientras vivamos los que conocimos a José Luis López Aranguren le evocaremos cada uno a nuestra manera, porque la evocación no es un calco de la situación que fue, sino una copia inficl, interesada, absolutamente personal, en la que evocado y evocador adquieren idéntico protagonismo. Todos los que estamos aquí - aunque alguno no le conociera directa, personalmente- podemos evocar a Aranguren. Yo le conocí hace bastantes años, cuando fui a su casa y me hizo sentar mientras concluían con él los de la televisión danesa. Hacía 24 horas que Aranguren había sido expulsado de la Universidad. Entonces era un hombre-poliedro, quiero decir que tenía muchas facetas, o, para decirlo con palabra que he de utilizar mucho en este texto, muchos yoes. Luego, con los años, y con una reiterada aunque discontinua relación, pude advertir que aparcó muchos de ellos, o los recluyó en su espacio más íntimo. Se expresó cada vez menos, fuera de sus actuaciones públicas. Cuando los que le conocimos desaparezcamos también, lo que han hecho sus discípulos - editar sus obras, promover estas conferencias - será el punto de partida para que los que vengan luego, detrás de nosotros, aun sin tener nada que evocar de él, sepan quién fue y qué fue lo que hizo. Así estará mucho tiempo en la memoria de muchos. 


\section{Yoes}

Pensemos en la siguiente frase:

\section{[1] qué idiota fui.}

No interesan las razones por las cuales el yo de ahora «piensa» que el yo de antes se condujo como idiota, puesto que se trata de un ejemplo. Para el caso lo mismo valdría la frase de significación opuesta:

[2] qué bien me fue ayer.

Mediante un acto de reflexividad, concepto que es más de gramáticos $\mathrm{y}$ lógicos que de psicólogos, uno se juzga a sí mismo. En realidad, parece que se juzga sólo a una actuación, o para ser más preciso, el yo de aquella actuación. $\mathrm{Y}$, desde otro punto de vista, o más bien desde otro ángulo, en la medida en que el yo que juzga y el yo juzgado pertenecen al mismo conjunto, lo que juzga es «una parte» y lo juzgado «otra». Porque pensemos que se pueda rizar el rizo de la manera siguiente:

[3] qué estoy diciendo, ique fui idiota ayer?, todo lo contrario.

Desde un punto de vista teórico se puede hacer una construcción encadenada de actuaciones, juzgadas a su vez sucesivamente, y cn una especie de casación ulterior, ser juzgado el juicio anterior acerca de la actuación, luego el juicio segundo, y el tercero, y así hasta el infinito.

Pasemos a otro ejemplo: alguien actúa, juzga que la actuación le está saliendo mal, la corrige, incluso le da el sesgo opuesto.

[4] te he dicho que eres tonto... perdona, no debi decintelo; el tonto soy yo en donde, por decirlo así, sobre la marcha, se juzga al yo de la actuación que se estaba realizando. $O$ esta otra frase, muy usual:

[5] me comporté mal; disculpeme, no lo volveré a hacer.

En este caso: un yo juzga a otro al que califica de malo, déspota o ineducado; crea otro que no es ineducado, sino cortés y hasta humilde, y está dispuesto a impedir que el $;$ anterior, del que ahora se arrepiente, reaparezca, lo que quiere decir cuando menos no que no se construya in mente, sino de que no se exteriorice. ¿Cuántos yoes aparecen aquí por parte del que lleva a cabo este acto de habla? Por lo mcnos tres:

1) el yo de ahora que juzga al de la actuacion anterior (que le merece ahora - antes no- el calificativo de idiota);

2) el yo de ahora que juzga la actuación de ahora (le debe parecer buena, porque es opucsta a la del yo anterior); $y$

3) el yo de ahora que promete que no aparecerán en el futuro yoes como el de antes. 
Hay veces en que se produce en mayor o menor medida un extrañamiento de ese yo que se mostró en la actuación. Es algo así como si no se reconociese el yo de la actuación:

[5] iqué raro!, ¿te dije que estaba mal lo que hacias?

Más complicado es el análisis de las frases que dijo don Fernando de los Ríos a don Manuel Azaña (y que éste recoge en la p. 137 de los Diarios robados y ahora publicados por Mondadori):

[6] iDiscúlpeme usted si la otra tarde no supe contenerme! Ese hombre [por don Indalecio Prieto] me hace parecer como no soy.

Aquí hay, entre otros yoes, un yo casi alucinado, tanto es cl rechazo que hace de él. Porque don Fernando muestra:

1) un yo que se disculpa ante Azaña por el yo que ante él mostró «la otra tarde»;

2) el yo evocado, el de «la otra tarde», por el que se disculpa, y que, por tanto, reconoce como suyo (si no para qué disculparse), del que dice que «le hace parecer como no soy»; es decir, que aunque reconoce que es de él no le parece de él'. Ese yo naturalmente es de él, no quicre verlo como tal porque lo repudia y le avergüenza, y entonces dice que le whace parecer» (ino ser, sino parecer!) como no es. Don Fernando de los Ríos se comporta como el niño sorprendido atrapando un lápiz que no es suyo y que afirma (y no cínicamente): «perdóneme, sé que el lápiz no es mío, pero me gustaba mucho y me ha hecho parecer ladrón, pero no lo soy». Finalmente,

3) el yo de «la otra tarde» al que se refiere no le parece construido por él, o por lo menos no sólo por él, sino por la intervención de don Indalecio, al que responsabiliza de su construcción. Sin Prieto, viene a decir, yo no sería el que fui. Ahora bien, por mucho que se nos provoque en una situación, por mucho alcohol o LSD que se ingiera, ide quién puede ser sino de uno el yo o los yoes que aparczcan?

Azaña, naturalmente, debía sonreír por dentro - a juzgar por lo irónico del texto- al oír a don Fernando culpar a Prieto de haber mostrado un yo en cl que no quería reconocerse y, sobre todo, que no le reconociese él. Don Fernando de los Ríos estaba dispuesto a no verse en aquel yo y pide a don Manuel Azaña que lo dé por no visto. Como cuando decimos:

[7] Te di ayer una bofetada... olvidalo

a sabjendas de que, por buena voluntad que posea el abofeteado, ha de contar con uno como aquel-que-puede-abofetearnos. Es lo que le ocurre a muchos no en el orden de las actuaciones en el espacio público, sino en el íntimo.

' "Parece» es sinónimo de "aparece», y entonces la expresión es más actual. Él aparece como no es. Creo que así debe ser interpretado el verbo «parecer» en cste contexto. 
[8] Pero ícómo se me ha podido pasar por la cabeza que yo pudiera desear que se muriera mi hijo?

que tan frecuentemente oímos a muchos, en circunstancias no muy dispares de aquellas otras en las que, de niños, se nos imponían pensamientos que, por su calidad de impuros, obscenos, en suma, de reprobables, tratábamos de apartar, los vivíamos a veces tan extrañadamente como para que los consideráramos «impuestos», autónomos, casi ajenos, impropios de nosotros $\mathrm{y}$, por tanto, extraños al yo observadorfjuzgador.

En términos generales, un yo hace de sujeto y otro yo hace de objeto para el primcro. Como ambos son del mismo sujeto, en la reflexividad se trata de un acto de desdoblamiento merced al cual se adquiere una transitividad virtual: el yo juzgado aparece como si fuera otro, distinto del yo juzgador. En psicopatología se denomina a este proceso disociación; pero como quien pronuncia la frase sabe que el yo que juzga y el juzgado le pertenecen, es decir, que son del mismo sujeto, hablamos de disociación como si. La frase [1] se puede reescribir de la manera siguiente:

[9] yo pienso ahora que yo fui idiota antes.

en donde hay dos yoes simultáneos en juego, como he dicho. Ambos se reconocen pertenecientes al mismo conjunto, un conjunto que tiene la propiedad de poder ser definido como alguien, o, para decirlo claramente, al mismo sujeto. Ambos yoes son, sin embargo, completamente distintos en el orden funcional, no sólo porque uno juzga y el otro es juzgado, sino en el orden moral, porque uno fue calificado de idiota por otro que no se considera tal y hasta insulta al primero. Pero son del mismo, no cabe duda, porque (lo damos por supucsto) el sujeto está mentalmente sano. Pero como hemos dicho, el yo juzgador puede ser juzgado a su vez, lo que quiere decir que hay un desplazamiento del yo que hace de objeto: ya no es el yo de la actuación, sino el yo que juzgó la actuación. La disociación como si puede ser calificada en el lenguaje de hoy como disociación virtual, como una disociación imaginaria.

El problema es distinto en el alucinado que nos relata:

\section{[10] me están llamando maricón.}

Aquí la disociación es real. Si nadie le dice que es maricón y él lo oye, entonces el yo al que atribuye la frase insultante es - para él- un yo de otro sujeto y no de él, que es insultado. En algún caso, del que tenemos experiencia por desgracia, el yo de la alucinación ordena al sujeto del yo alucinado que se lance al vacío para volar o que mate a alguien. Ni quien le insulta, ni le invita a volar, ni le ordena que mate, son reconocidos como yoes de él, sino de alguien (otro sujeto) distinto a él que le insulta, le invita a volar o le ordena matar, y al que le reconoce poderes sobre él y al que ha de obedecer. Que parte de él adquiere autonomía y es vivida como ajena, como otro, lo revela la frecuencia - prácticamente la regla - con que el alu- 
cinado dialoga con sus voces, rechaza o acepta lo que afirman de él, negándoles o dándoles la razón. No hay duda: el alucinado está desdoblado en el yo que alucina y el yo alucinado. A veces hay también polialucinaciones, y son muchos los yoes que, siendo todos de él, son considerados como de otros. Son sujetos multidesdoblados. No voy a aludir a estos sujetos más que en algún momento.

El problema interesante es el de la relación entre ese yo que he denominado yo de actuación y el yo denominado juzgador. Porque es algo más que juzgador. Si sólo fuera juzgador se limitaría a observar al yo que actúa y a emitir un juicio acerca de la estrategia seguida en la actuación. Pero hay algo más, y con ello anticipo algo sobre lo que me extenderé luego: ese yo observador/juzgador tiene poderes sobre el yo de la actuación, como lo prueba el que tras la observación/juicio que licvó a cabo pucde modificarlo, más concretamente, irlo modificando según los resultados parciales que obtiene. Ese poder del primero de los yoes es notorio cuando, como hemos de ver posteriormente, se trata de proyectos de yo que serán exteriorizables («cómo haré», «qué diré», "cómo me saldrá», etc.).

\section{Yoes funcionalmente distintos}

En todos estos casos - y cualquiera sea el ejemplo que se analice-, hay un yo cognoscible (al que he denominado yo-objeto), que actúa, y por actuar se hace observable, y un yo conocedor del primero (que he denorninado yo-sujeto), que observa —observar es una metáfora; en realidad conoce- y juzga al anterior, porque no tiene más remedio que hacerlo, como se hace ante todo objeto con el que nos enfrentamos; un juicio que, naturalmente, es un acto de cognición, de existencia, de reconocimiento e identificación, etc., y del que se derivarán luego, si es el caso, calificaciones morales, estéticas, de eficacia o de la índole que sean. Una vez conocido el yo-objeto, gusta o no gusta, se acepta o se rechaza por parte del sujeto, y si se rechaza tiende a verse: a) como de uno, a pesar de todo, y, por tanto, susceptible de corrección ulterior o de desuso, y b) en el otro extremo, como no de uno, como el alucinado. En los estadios intermedios está el extrañamiento, la negación aparcnte del yo que se menosprecia. En suma, todos esos estados a los que me he referido en la descripción que he hecho con anterioridad con la pretensión de poner unos ejemplos.

\section{Un modelo}

Como conclusión primera quisiera declarar que lo que trato de ofrecer ahora es un modelo que permita dar cuenta de estos hechos - o estas experienciasa las que he hecho mención y, si es posible, de cualesquiera otras que se puedan traer a colación. Pero antes quisiera citar por extenso un precedente 
- habría muchos más en la literatura, pero ninguno tan profundo y agudocomo el de un autor al que apenas se vuelve en la actualidad, ni tan siquiera por aquellos a los que habría que considerar como deudores de sus tesis en lo que concierne a esta cuestión del sujeto y del yo. Me refiero a William James.

Como ocurre muchas veces en el ámbito del conocimiento, no ha sido suficientemente considerada su tesis (lo fue por él, aunque no ha sido seguida por otros ajenos a él), pese a sus posibilidades insospechadas para una clarificación de procesos psicológicos y psicopatológicos hasta ahora ininteligibles. Si se compara el capítulo XII del Compendio de Psicología de W. James con cualquiera otro de las psicologías de la época y posteriores advierte uno su formidable penetración, por una parte, y, por otra, cómo las afirmaciones derivan del análisis de actuaciones tanto empíricas cuanto introspectivas. Dicho sea de paso, a mi parecer, la no utilización de las tesis de James a este respecto deriva de que es el primer psicólogo, antes incluso que McDougall -aparte de su aportación al concepto y descripción de la corriente de la conciencia, en la que se sumerge por decirlo así en el análisis del propio pensar, y que no ha sido aún superado-, que en el análisis del comportamiento se sale de la consideración solipsista del sujeto para concebirlo siempre en términos de relación sujeto/objeto.

James comienza por distinguir los dos yoes de una actuación, cl yo cognoscible o mí, y al que pertenece todo lo mío, y un yo conocedor del primero, al que llamará yo conocedor. «En el sentido más amplio posible, el mí de un hombre es la suma total de cuanto puede llamar suyom, dice James. Describirá entre las cosas que podemos llamar mías las materiales (el cuerpo propio, el traje -James hace suyo el dicho inglés de que el ser humano se compone de cucrpo y ropa-, la familia, la casa), sociales (del cual dice así: «el mí social es el reconocimiento que del yo de una persona tienen los demás», y por eso añade: el yo social de cada cual «está en la mente de los demás») y espirituales, que es la imagen que tenemos de nosotros mismos en orden a nuestras capacidades y limitaciones, el pensamiento que tenemos «cuando pensamos en nosotros mismos». Luego James hablará de qué forma todas estas cosas mías darán lugar al autoaprecio, a la autocstima, y cómo tales cosas mías son logradas y, una vez que lo han sido, cómo tienen que ser mantenidas y defendidas.

\section{Nivel del yo y nivel del sujeto}

Ahora bien, el yo conocedor y el cognoscible no están en el mismo nivel lógico. La teoría de los niveles de lenguaje, que desarrollaron Bertrand Russell y Rudolf Carnap, permite hablar de que el yo conocedor está «por encima» - -es una metáfora espacial- del yo cognoscible. El yo conocedor debe estar «más alto», como en una torre, desde la que dictaminar acerca de los yoes 
del suelo (prosigo con metáforas espaciales) que él ha dejado pasar desde dentro de sí mismo a la realidad. Desde el punto de vista lógico, el yo conocedor está en un nivel lógico de segundo nivel, frente al yo cognoscible, que lo está en el primero. Si el yo cognoscible corresponde al lenguaje-objeto, el yo conocedor es un metalenguaje del primero. Habría, para decirlo de otra forma, en efecto, un yo-objeto (el yo que actúa) y un meta-yo (que lo ha proyectado, lo ha hecho y juzga al anterior). O para ser más exactos, muchos yoes-objeto y un solo meta-yo. O con un término que es necesario reivindicar (en psicología y psicopatología y también en psicosociología - lo ha hecho Touraine recientemente-): un solo sujeto.

\section{Concepto de sujeto. Actividad y actuación}

La palabra meta-yo suena mal, pero puede ser usada para situar el yo conocedor como categorialmente superior a todos los yoes cognoscibles. A ese meta-yo es al que llamo, y llamaré, sujeto. La palabra sujeto permite su consideración como conjunto de todos los yoes posibles.

¿Cómo conceptualizar al sujeto?

El sujeto es una actividad mental dependiente de la funcionalidad de un órgano que es el cortex cerebral, y que hace posible que de algo, lo que se hace verbal o extraverbalmente, es decir, de las actividades que rcalizamos, se pueda afirmar que son actuaciones de alguien. El sujeto puede decir que son suyas; los demás, que son de él, es decir, suyas también, y por ellas se le reconoce. Conviene advertirlo: actividades son hablar, coger, andar, mirar, reír... que hoy puede hacer un robot. Actividad es hablar; actuaciones, insultar, alabar, reñir, discutir, etc.; la actividad coger permite actuaciones como recoger, retener, robar, entregar; la de andar, pasear, vigilar, huir, exhibirse; la del mirar, observar, escrutar, atender... Una actividad se transforma en actuación cuando se modula de acuerdo a las reglas que impone el contexto en el que y para el que se realiza. Las actividades son pattems básicos ya estructurados neurológicamente. Parafraseando a Austin respecto de los actos de habla, la actividad es la locución, la actuación la ilocución. Quede de antemano este axioma: la actividad es una condición necesaria pero no suficiente para la actuación (realización o performance). Hay situaciones en las que se llevan a cabo actividades ( $y$ no precisamente por un robot) y no actuaciones: un tic en el que se parpadea es una actividad, no una actuación, que sí lo es un guiño; un epiléptico que durante la crisis de pequeño mal ejecuta movimientos de chupeteo, no chupa en verdad como lo haría con un caramelo, ni si anda unos pasos se puede decir que pasea o huye; de un sonámbulo que se levanta de la cama y anda no se puede decir más, porque no pasea, no huye, no se esconde. Se puede afirmar que el sujeto lleva a cabo actuaciones con aquellas partes del organismo con las que puede hacer lo que en fisiología se denominan actos voluntarios (o actos intencionales). Así, gracias a que con las manos 
se puede coger es posible robar, llevarse la cuchara a la boca o firmar; gracias a que el brazo puede elevarse con la mano estirada, se puede saludar al modo fascista o detener el autobús.

Las actuaciones son, justamente, el yo en el que el sujeto delega para su relación con la realidad, o, para ser más preciso, con la situación.

\section{Sujeto y yo}

Las actuaciones remiten al sujeto que las hace, porque son «indicios» acerca de cómo es él, cuáles son sus intenciones, los motivos que le llevan a actuar, etc. Searle dice algo análogo al tratar de qué es un acto de habla en sentido estricto, cuando afirma que sólo lo es aquel ruido o aquella marca gráfica que se suponen producidas por un ser con ciertas intenciones. Es curioso que a Searle se le introduzca el sujeto por la puerta de atrás, como les ocurre a los cognitivistas, por ejemplo, a Ruiz Vargas al tratar de la memoria episódica, esto es, la memoria evocativa, que ha de definir como aquellos recuerdos explícitos de los acontecimientos que «vivimos personalmente».

Mientras las actividades no son intencionales -en el robot, en el tic, en la epilepsia, etc.- las actuaciones son siempre intencionales y su intención, no observable, es siempre «consabida»: es una hipótesis (la existencia de intencionalidad) imprescindible (mientras no se demuestre que no existe). Sobre ese supuesto - la intención con la que se supone que se efectuó la actuaciónse sustenta la interacción. En la interacción cada uno responde a la actuación del otro por la representación de la intención que le presupone. Miramos a un desconocido y nos da una bofetada por el desprecio que nos presupone hacia él, o se acerca y comenzamos afablemente a conversar.

Si las actuaciones remiten «hacia atrás», hacia el sujeto, no son todo el sujeto, sino parte de él, algo así como su representante, su delegado para esta actuación; en suma, el yo con el cual se presenta el sujeto en esta situación para llevar a cabo en ella la re-presentación que se le exige. Cada actuación requiere que el sujeto se presente en el escenario con el yo más adecuado. Para cada actuación, el sujeto construye un yo que, como personaje, le representa de la mejor manera posible en el contexto constituido o por constituir. Terminada esta representación se inicia otra, para la cual el sujeto, apartado el yo precedente, construye otro para la siguicnte escena, y asi sucesivamente. De aquí, una vez más, la necesidad de diferenciar el sujeto del yo, que le pertenece porque es un módulo de él. El yo es al sujeto lo que un miembro al conjunto al que pertenece. Por eso $u n$ yo no es el sujeto. Si lo fuera no podría hacer más que una y siempre la misma actuación. Pero hemos visto que se hacen muchas y muy varias actuaciones, a veces contradictorias. Esta consideración de la unidad del sujeto y la multiplicidad de sus yoes es interesante y subsana las dificultades y las consecuencias graves de la consideración opuesta. Definir al sujeto por uno o varios de sus yoes -como habitualmente se hace 
en la cotidianeidad - es un gravisimo error, con efectos deletéreos para el objeto sobre el cual se hace y con graves limitaciones para el sujeto del juicio. De cada uno, a quien se nos conoce como sujeto sólo por la singular excrecencia de uno o varios de nuestros yoes, hay tantas posibles definiciones como actuaciones verificadas con ellos a lo largo de la vida. Cada cual ha visto del otro un grupo de ellas, y conoce algunas más por mera referencia. ¿Cuál es el que permitiría una definición de todo él? Por importantes que sean algunas de estas actuaciones, a ninguna cabe otorgársele la categoría de definitoria de la totalidad ideal o teórica que es el sujeto. Un ejemplo: definir a un sujeto como asesino porque ha matado a algujen o a varios, es tan impropio como definir a alguien como paseante porque se le vio pasear un día o dos. No niego que puedan usarse expresiones de este tipo en el uso coloquial, pero hay que tener cuidado con ellas. Las palabras, mucho más las que entrañan definiciones, no son inocentes. Por esa regla falaz, de un loco se afirma que no puede hacer más que locuras, y eso no es verdad: en plena locura, una parte del sujeto (no loca, por tanto) juzga a veces como posiblemente loca a otra parte de él, y a mayor abundamiento, esa parte del sujeto loca, que delira y alucina creyéndose perseguido y envenenado, lee, pasea, come o fuma, $\mathrm{y}$ tales actuaciones o no son o no tienen por qué ser necesariamente locas. Los juristas lo saben bien desde hace más de un siglo: un acto delictivo es inimputable aunque un sujeto esté diagnosticado correctamente de enfermo mental, si el acto por el que se le juzga es un acto loco, porque muchos enfermos mentales roban, matan, violan o comen cuerdamente y no son, pues, actuaciones/síntomas de la locura que, sin embargo, padece en otros módulos de él. El sujeto de las actuaciones no se define sin riesgo de caer en un razonamiento inductivo/reductivo. Pero si no se le puede definir sí se le pucde describir a partir de los yoes observados, esto es, a partir de cada una de sus actuaciones, y juzgar éstas desde el marco que se adopte (moral, jurídico, estético, intelectual, etc.), sin que se involucre al sujeto más allá del contexto desde el que se le define. Por eso, aunque posteriormente aludiré a ello con mayor detalle, la biografía de alguien es la descripción de sus actuaciones (algo que se ha comprendido tardiamente, y que yo sepa fue Painter, el biógrafo de Proust, el primero que procedió implícitamente con este método). Aun así, de un mismo sujeto hay tantas biografías como biógrafos, porque cada uno de ellos «sclecciona" positiva o negativamente, de entre las infinitas actuaciones del biografiado, aquellas que «cierran» y «completan» su teoría previa acerca del sujeto en cuestión,

De manera que sujeto es el sistema del organismo mediante el cual se construyen yoes adecuados para una secuencia de actuaciones en la realidad, o los aparca para su utilización ulterior en una situación semejante, o los destruye llegado el caso, o se les escapa y se salen del sistema, como en el caso de la alucinación esquizofrénica, etc. El sistema del sujeto comprende tanto al sujeto como a los yoes procedentes de él. El sujeto juzga la afortunada o desafortunada 
construcción del yo para la actuación (no entramos ahora en la influencia de los otros en la interacción respecto del juicio que el sujeto hace del yo que construyó, que es, desde luego, decisiva). Usando para este momento un léxico computacional, diríamos que el sujeto es un directorio y los yoes módulos o archivos incluidos en él (comunicables entre sí por el hecho de su pertenencia al mismo conjunto).

El sujcto, pues, es constructor de yoes y los yoes instrumentos del sujeto para la adopción de una «forma de vida» que está acuñada en el discurso de la fisiología del sistema nervioso central desde comienzos del XIX, la llamada vida de relación. El sistema nervioso central es el que hace posible la actuación voluntaria, relacional, intencional, es decir, el que hace posible que el organismo desempeñe las funciones de sujeto.

\section{Construcción (ariticipada, proléptica) del yo}

Sólo en situaciones de urgencia, de perentoria improvisación, el sujeto construye cl yo «sobre la marcha». La mayoría de las veces el sujeto lo hace a partir de una teoría o hipótesis pragmática sobre la realidad que ha de encontrar y, de acuerdo a ella, el sujeto construye el que considera proyecto de yo más adecuado. Lo matiza luego, cuando actual, o lo deconstruye y reconstruye en parte, según el caso, y desde luego lo controla en su quehacer práctico. Nunca ese yo anticipado, proyectado, se vuelca tal cual sobre la realidad (salvo en situaciones de excepción). Las más de las veces, como el contexto posee un tanto mayor o menor de imprevisible, el sujeto modifica el yo proyectado (su estrategia) con vistas a una actuación exitosa. En pocas palabras, el yo no se improvisa, sino que ha de ser adaptado de manera extremadamente flexible al contexto, de acuerdo al propósito de su actuación y a las posibilidades de éxito al respecto.

Estos proyectos de yo son, pues, anticipaciones, prolepsis del yo que se ha de representar; para seguir con el símil teatral, ensayos (no públicos) de yo. El término prolepsis lo tomo, para este momento, de Victor von Weiszaecker, que lo usó para la interpretación de funciones neurológicas tales como las anticipaciones que permiten el funcionalismo cuasi automático. Estas prolepsis de yo muestran de manera inequívoca que el sujeto no se relaciona ingenuamente ante la realidad ${ }^{2}$, sino inicialmente ante sus realidades supucstas, lo que he calificado de teorias pragmáticas sobre la realidad. Preparar una conferencia - es un ejemplo que propongo por su notoriedad-es construir una teoría acerca de la realidad que se ha de encontrar, e incluye en ella hasta una hipótesis acerca del nivel de formación e intelección del que puede ser

"Sabemos que esto no ocurre ni en el campo de la percepción: percibimos en buena parte lo que de antemano seleccionamos para serlo, es decir, que actuamos perceptualmente sobre unt marco previo. 
el auditorio. Ahora bien, ¿qué de la realidad proléptica y, por tanto, imaginada se encuentra el conferenciante? ¿Cuál supondrá al iniciarla, desarrollarla y concluirla? ¿No se ha tenido que modificar la construcción del yo proléptico para hacer de él aquel con el que se actúa? Hay, pucs, una ctapa en los yoes actualizados que han sido ensayos de yo, proyectos de yo, yoes imaginados.

No se trata, pese a todo, que se haya de poseer una teoría acerca de la realidad, o mejor, del contexto en el que nos hemos de encontrar. Hay que construir una teoría de ese yo que ha de actuar en ella, de forma que sea lo que Garfinkel denomina un yo ad hoc. Las adecuaciones del yo al contexto dependen de que se haya logrado construir un yo ad hoc; en caso contrario, de un yo non ad hoc se derivan consecuencias en las que no podemos entrar en ese momento.

\section{Control del yo}

No hay yo proléptico anticipado que se pueda implantar en el contexto en el que ha de actuar, porque la misma inclusión del yo del sujeto en él supone una modificación del propio sujeto. Hay, pues, y ésta es una de las funciones del sujeto, que re-adaptar el yo a medida que él mismo modifica con su actuación la realidad antes supuesta. Por tanto, el sujeto no ha concluido su tarea respecto del yo para una secuencia de concretas actuaciones con su construcción anticipada, sino que, como un proceso que es - la actuación posee una estructura narrativa-, tiene ahora la misión de hacer que se mantenga dentro de los límites que marcan el contexto, salvo que, a propósito, le proponga la transgresión de las reglas contextuales y contextualizadoras. En resumen, el sujeto controla al yo hasta el cese de su necesidad de él. En todo caso debe advertirse que el yo inicial de una secuencia de actuaciones no tiene las más de las veces la misma conformación que $\mathrm{cl}$ yo de sccuencias ulteriores y que el yo final, que puede resultar incluso opuesto al inicial.

\section{El sistema sujetolyo}

¿Qué hace el sujeto con sus yoes? Algunos no vuelven a ser usados, porque no hay ocasión para ello, o porque no deben ser usados (los motivos del sujeto para esta abstención son muy varios: intelectuales, morales, estéticos, y, si se puede decir en una sola frase, se trata de yoes desafortunados con los que el sujeto no logró el propósito pretendido en su actuación). Otras veces se trata, con mayor o menor eficacia, de destruir tales yoes (mediante formas racionalizadas de negación - «no hice así»-). Por último, las más de veces se asumen y se almacenan, porque hay una memoria de yoes, la memoria evocativa, lo que llamamos evocaciones — una palabra, por cicrto, de la que los cognitivistas huyen como de la peste-, en la cual el sujeto no se limita 
a recordar la situación que vivió, sino a él re-viviéndola. En resumen, el sujeto tiene su arquitectura modular, para usar de una expresión de Fodor y de Sperber respecto de la mente en general.

\section{Contextos del yo}

Los yoes proyectados, imaginados, no siempre son exteriorizados. Pueden ser inhibidos ante el temor del sujeto a su fracaso con él, o sencillamente porque, al verificarse la relación con el contexto, se advierte que no tienen ya «razón de ser» y el contexto es muy otro.

En este sentido hay que aludir, aunque someramente, a los espacios o contextos de actuación del yo.

Hay tres espacios de actuación: 1) el de los contextos empírico-públicos, hechos por y para la exhibición; 2) el de los contextos empírico-privados, hechos por y para aquellos a los que se autoriza el paso a un contexto de posible aunque no permitida observación por parte de los extraños a él, y 3) cl de los contextos intimos, que son a su vez de dos tipos: a) el de los yoes imaginados como proyectos o prolepsis de yoes, que se quedan en tal, pero que tienen, por decirlo así, su pie en la rcalidad, su contacto con ella, como no puede ser de otra manera, y b) el de los yoes fantaseados. La distinción entre imaginación y fantasía, sobre la cual me apoyaré, fue establecida por Coleridge. En la psiquiatría francesa del siglo pasado, al ocuparse de los delirios, se hacía ya la distinción implícita entre imaginación y fantasía, y se hablaba de delirios imaginativos y delirios fantásticos. Posteriormente, también en la psiquiatría alemana, y por parte de Karl Kleist, el fundador de la escuela de Frankfurt, se habló de fantasiofrenias, delirios de fantasias, frente a las paranoias, que serían los delirios imaginativos.

\section{Yoes en contextos fantaseados}

Los yoes imaginados o proyectos de yo son completamente distintos a los yoes fantaseados. Imaginación y fantasía son dos actividades mentales distintas y con funcionalidad dispar. Imaginamos sobre la realidad; fantaseamos de espaldas a la realidad, sustituyéndola. Pues bien, construimos - y a la perfecciónyoes en nuestras fantasías cuando nos apartamos de la realidad y abdicamos momentáneamente de proyectar cualquier actuación sobre ella, dedicados a soñar despiertos realidades virtuales. Mientras en el mundo imaginado no se pierde cl contacto con la realidad, precisamente porque se aspira a actuar en ella a continuación, y lo más eficazmente posible, con la fantasía no es así. En ésta el sujeto se mueve «a gusto», construye el yo literalmente «a su placer», porque la fantasía es la realización fantástica y vicariante del deseo que de otra forma, es decir, fácticamente, no puede lograrse en la realidad. 
Los yoes fantaseados tienen de común el hecho de no scr perturbados por nada ni por nadie (pueden interrumpirse por alguna intrusión de la realidad, y entonces nos «despertamos», porque, como se dice, las fantasías son ensonaciones compatibles con el estado de vigilia), no precisan modificación alguna impuesta desde fuera del sujeto de la fantasía. La «realidad» fantaseada es una construcción ad hoc al servicio del sujeto, en la que, por tanto, nos fantaseamos al mismo tiempo que fantaseamos con los demás. Son yoes íntimos a los que nadie tiene acceso más que el sujeto. Llamo la atención sobre $\mathrm{cl}$ esfuerzo, a veces inútil, para lograr que se verbalice sobre ellos (a diferencia de los sueños, que se narran sin resistencia alguna). La razón es la siguiente: se trata de yoes tan alejados de los yoes públicos y aun los privados de los que los demás tenemos noticia, que el sujeto siente un invencible pudor de confesarlos. Se trata de yoes unas veces inmorales, otras ridiculos y, por tanto, patéticos. Si se muestran, dejan al sujeto a la intemperie ante el que escucha, por el carácter de alternativa al desivalimiento y fracaso que implican en la realidad. Nada hay más revelador del fracaso de una criatura humana que la verbalización de sus fantasías, tan distantes de sus logros, tanto más pobres en la vida real, cuanto más exultantes en la vida fantascada. El paradigma de este tipo de cosas de construcción de yoes y situaciones fantaseadas y grandiosas lo tenemos en los masturbadores, no el masturbador ocasional, sino cl adicto a ellas como recurso ante la impotencia de sus yoes para contextos reales. (Entre paréntesis: es más fácil la verbalización de las fantasías inmorales que las ridículas, como ya señaló Rousseau en sus Confesiones y no es preciso aclarar las razones de ello.)

\section{Funciones del sujeto}

La función del sujeto como sistema es la de crear yoes, que han de poseer cuatro características básicas: propositividad, prolepsis, propiedad y comunicabilidad.

Respecto de la propositividad, todo yo se construye con un (o más de uno) propósito. Es lo que caracteriza toda actuación. La actividad se eleva al rango de actuación cuando se instrumentaliza al servicio del propósito del sujeto. Todo acto psíquico está dírigido a, decía Brentano. Por eso identificaba el acto psíquico con acto intencional, que en el contexto de Brentano no significa motivos, sino el mero ir hacia algo, hacia un objeto, por fuera de él. Traigo a colación a Brentano con una finalidad, a saber: todas las actuaciones del yo son mentales y, por tanto, todas, sin excepción, se supeditan, gracias a su propiedad intencional, al propósito del sujeto, que, en última instancia, se resume en la fórmula siguiente: hacer vida de relacion, es decir, establecer una relación de él como sujeto con el otro (otro sujeto, un objeto propiamente dicho). 
La segunda, es la construcción anticipada de yoes ad hoc para la actuación y su modificación en el curso de la misma, a la cual me he referido con suficiente amplitud. Y su corolario: el almacenamiento modular de los yoes. La construcción de yoes está indisolublemente ligada a la tarea propositiva del sujeto. No hay sujeto sin propósito, y para llevarlo a cabo precisa construir el yo que hemos llamado ad hoc o recoger alguno de los preexistentes.

La tercera es la de propiedad. El sujeto ha de reconocer todos sus yocs como de él, como propios de él, como de su propiedad. Porque cada yo es suyo, como decía W. James, y aun exterioriado no pierde el sujeto su tutela y su propiedad. Salvo en situaciones esquizofrénicas o que se aproximan peligrosamente a ellas, el sujeto asume todos los yoes. Esta función es la que Jaspers reconocía como de pertenencia al yo. Nosotros decimos de pertenencia al sujeto. Jaspers hablaba también de mismidad. Pese a la multiplicidad y heterogencidad de yoes, a que éstos son no sólo distintos, sino contradictorios (se es mendaz y veraz, honesto y deshonesto, derrochador y tacaño, generoso y cruel... y señalo sólo situaciones bipolares), son del mismo (y es, pues, el mismo) sujeto.

La cuarta, derivada en parte de la anterior, es la de la comunicabilidad intermodular de yoes. Todos tenemos experiencia de cómo, a partir de una situación, o de la evocación de una situación, surgen otras arracimadas, temáticamente distintas y que, sin cmbargo, se comunican entre sí a través del contexto en el que se dieron o de la sincronía con que tuvieron lugar.

La patología del sujeto afecta a una u otra, y a veces a todas estas propiedades del mismo. La psicosis es un claro ejemplo de inasunción de yoes por parte del sujeto, y la alucinación y el delirio - con su proyección ineludible, como mecanismo de él- son expresión de ello. Pero hay otras patologías que afectan a la comunicabilidad intermodular o a la «negación» mnéstica - el olvido «conveniente», nietzscheofreudiano-, que si bien permite la máxima homogeneidad del sujcto, y la homeostasis subsiguiente, por otra conlleva su empobrecimiento. Volveré sobre esta cuestión.

\section{Yo y yoes}

En muchos contextos podríamos decir que actuamos con un solo yo, por to menos en lo que respecta al yo exteriorizado, público. Cuando se da un pésame, la actuación relevante es la de un yo apenado por la pena del amigo. A la espalda de ese yo público existen yoes meramente imaginados que no se actualizarán por no ser pertinentes. ¿Puedo alegrarme y exteriorizar mi contento por la pérdida de ese ser por el que doy el pésame al amigo? Quiero indicar tan sólo que junto al yo protagonista, actualizado, hay yoes que no lo son, salvo que se autonomiccn y exterioricen a nuestro pesar, cosa que ocurre con frecuencia colocándonos en situaciones enojosas. El yo tiene siempre carácter de personaje representativo del sujeto, lo mismo si es veraz (en cuyo caso 
emerge sin dificultad alguna) que si es mendaz $y$, en la expresión habitual, se trata de un yo simulado. Deseo aclarar a este respecto que en esta tcoría del sujeto no hay lugar para yoes simulados. ¿Qué se quiere decir con ello? ¿Que el yo que se ostenta es un yo impuesto por las reglas del contexto? Así son todos, salvo en los yoes íntimos, y aun en éstos no dejan de regir en ocasiones reglas contextuales más propias de los yoes públicos, pues es sabido que la introyección o internalización de normas morales imposibilitan la construcción del yo intimo deseable. Lo interesante de situaciones como éstas es el hecho de que el sujeto pone en marcha yoes de distinta indole según sean para actuaciones públicas, privadas o íntimas, y que en ocasiones, junto al yo exteriorizado y, por tanto, público, otro permanece en el espacio privado o en el intimo. El sujeto construye multiples yoes - a veces contradictorios- para determinados contextos, cada uno de los cuales resulta ser un yo ad hoc, pese a lo contradictorio de ambos. Es una forma de postular el principio de sobredeterminación (Freud) en lo que concierne a los propósitos del sujeto.

William James llama la atención acerca de que en el comienzo de nuestra vida social propiamente dicha, hacia la adolescencia, existe la posibilidad de fantasear con multiples yoes que confieran al sujeto, a su vez, una identidad varia, polimorfa, y no limitada a un género relevante de yo, de actuaciones. Es decir, en ese momento se ofrece al sujeto la posibilidad de construcción de yoes de relevancia idéntica, $o$, mejor dicho, de máxima relevancia para todos ellos. Luego, ha de sacrificar muchos en favor de uno o varios. Con su lenguaje y su pensamiento tan clásico añade: «realizar uno solo de los yoes es, más o menos, suprimir a los demás. Así, quien quiera salvar su yo más cicrto, más intenso y profundo, habrá de repasar cuidadosamente la lista - se refiere a sus yoes posibles, potenciales-, elegir un número y jugarse en él su porvenir. Los demás yoes quedarán oscurecidos, como si no existieran; sólo la suerte del yo elegido será la real... (en el sentido de) triunfos y fracasos».

El análisis de las fantasías demuestra -en otra visión del problema- que el sujeto no construye un solo yo para cada situación, sino muchos y todos al mismo tiempo. Una fantasía es una narración en toda regla, en la que el protagonista es desde luego un yo fantaseado. Pero los demás - los que actúan de comparsa - no son en realidad los otros, sino nuestros otros, también fantaseados. Cuando alguien fantasea con la ceremonia en la que se le entrega el Nobel, hace «su» rey y reina de Suecia, «su» presidente de la institución y «su» público, esto es, organiza la representación en la que gustará del placer del éxito (no puede ser de otra manera, para eso se fantasea, aunque a veces el éxito acabe con una fantasía de muerte y, tras ella, de inmortalidad). Pues bien, esos yoes subsidiarios pertenecen al sujeto con el mismo rango que el yo protagonista, como en los sueños con el vecino también el vecino es el soñante en la medida en que somos los constructores de su actuación. Usando un término de Bajtin, el sujeto, como órgano productor de yoes, es intrínsecamente polifónico en cada secuencia de actuaciones. 


\section{La relación sujetolotro(s), El yo semiótico}

El éxito o fracaso de los yoes construidos se prueba en la interacción. Son los demás los que «certifican», con su comportamiento para con nosotros, el éxito o fracaso del nuestro.

Conviene recordar lo dicho acerca de la construcción del yo como proceso que se inicia con carácter anticipatorio (prolepsis), previo a la actuación. El sujeto proyecta un yo para la situación que imagina y en la que va a actuar. Sobre la marcha, como resultado de la interacción misma, el sujeto modifica el yo y su actuación, lo reajusta con el propósito de que el final sea exitoso. El yo construido de antemano -el proyecto o prolepsis de yo- es aquel que el sujeto conjetura como el adecuado para su «teoría» de la situación por venir. De la interacción yo/situación real surge el yo final, del que el sujeto dispondrá para eventuales situaciones ulteriores análogas, y al que $\mathrm{el}$ sujeto juzga como un objeto más («qué bien me salió el trato de ayer», "qué estúpido me comporté anoche»). Pero, como decía James, ese yo de la actuación está cn la mente de los demás, para los cuales se actúa.

¿Qué es, entonces, el yo?

El yo es la imagen instrumental con la que el sujeto se presenta en y para la situación; un intermediario del sujeto para la situación. Actuamos en cada situación representados por un yo, que hará «lo que pueda» para el logro de la mejor intervención y, con ello, la mejor imagen del sujeto. El yo es la representación con la que el sujeto se propone obtener de los demás la mejor de las imágenes posibles, cara a la interacción y a la satisfacción desiderativa derivada de ella. Esto quiere decir que el sujeto construye el yo como un sistema de signos, como un discurso articulado; en suma, como un mensaje, mediante el cual pretende que el otro, por una parte, se forme la imagen que él anhela provocar y, por otra, que acepte su propuesta. La pregunta que implícitamente hacemos en toda interacción es una pregunta sobre el sujeto, a saber: ¿qué se propone al hacer lo que hace? Alguien camina ante alguien, se dirige a un determinado lugar, pero, ino pretende que el que le observa adquiera de él una determinada imagen, la que sea, de clegante, de abstraído en graves problemas, de orgulloso o displicente? ¿Qué imagen intenta que los demás construyan de él cuando da una clase o pronuncia una conferencia? El yo, pues, es una construcción semiótica al servicio de la semántica del sujeto con miras a que el receptor asuma la imagen ofrecida y le confirme en su identidad. En el léxico comunicacional, el yo es el mensaje; el sujeto, el metamensaje en el proceso de interacción. Por eso nadie puede hacer otra cosa que imaginar el sujeto a través de las concretas actuaciones de sus yoes. $E l$ 
yo es el signo que denotamos; el sujeto, el significado que le atribuimos tras sus actuaciones ${ }^{3}$.

El yo (semiótico), pues, es un discurso del sujeto cuyo tema adquiere rango de argumento. El proceso de construcción y desarrollo de un yo es análogo al de una narración, y posee, en efecto, una estructura narrativa: texto y tema, este último con introducción, desarrollo y final del argumento. Aun el yo actual es el resultado de una narración que el sujeto ha construido previa a la actuación, la prosigue en la actuación y la cuImina muchas veces en su intimidad, cuando recaba qué hizo y no debió hacer o qué no debió hacer e hizo. Cada yo, para utilizar una metáfora, es una película del sujeto.

\section{Estructura y géneros de yo}

No es éste el lugar para desarrollar dos cuestiones que son de gran interés, a las que haré una breve alusión, después de aludir a la estructura narrativa que deviene en la construcción de un yo. Una, que el yo debe considerarse como discurso del sujeto; otra, que posee un determinado género.

Precisamente porque el yo es una representación en ese escenario que es todo contexto tiene su introducción, desarrollo y final (en el mejor de los casos, porque a veces se intcrrumpe de manera abrupta, pero eso ocurre a veces también en el teatro stricto sensu). Se puede contar lo que ha pasado aquí esta tarde: $P$ entró de esta manera, se sentó, venía vestido de tal y tal forma, su actitud era ésta o la otra, habló sobre el tema tal o cual, dijo que..., expuso el tema $\mathrm{X}$, durante la exposición hizo A, B y C, y luego acabó del modo siguiente... Como tantas veces, el proyecto de yo ha de ser modificado sobre la marcha, y la narración vivida, la actual, la que en este momento tiene lugar, está repleta de anacolutos, incorrecciones, retrocesos, desviaciones del tema principal en mayor cuantía que la narración a posteriori de lo recordado. Mientras nuestras actuaciones «las contamos» a medida que transcurren, en la evocación contamos lo pasado y ponemos orden, limites, rellenamos vacios y subsanamos fisuras.

La segunda cuestión a la que quiero aludir es que los yoes, como narraciones del sujeto, son genénicos. Como discursos, como narraciones, además de la estructura a que me he referido antes, poseen un tema o argumento. Hay géneros de yo, como hay géneros literarios o filmicos. Nuestras actuaciones pertenecen a un género, dependiendo del yo relcvante que se pone en juego para la misma. En las actuaciones fantaseadas esto es evidente, porque no hay imposición alguna de otros yoes que son requeridos en la actuación sobre la realidad. En los yoes públicos hay actuaciones genéricamente intelectuales,

${ }^{3}$ Porque el yo es el que actúa de acuerdo a los propósitos del sujeto. De acuerdo con el aforismo wittgensteiniano se podria decir: no preguntéis por el sujeto, sino por lo que hace (con el yo). 
como las hay del género erótico, pático, moral o estético. La polifonía del sujeto se revela en expresiones como las siguientes: «dio la conferencia, pero sobre todo vino a lucirse», "enseñaba logaritmos y ligaba que era un primor». Pero en los yoes y situaciones fantaseadas no hay necesidad de construir dos o tres yoes simultaneamente, uno para el escenario público, el otro o los otros para el escenario privado o intimo, sino que se elige uno y sólo uno para el éxito de una y sólo una actuación. Las fantasías, es decir, los yoes y los contextos asimismo fantaseados para ellos son de un género, como lo son las novelas. Las fantasías organizadas y sistematizadas a lo que se asemejan es a novelas y, por su estructura narrativa, se pueden contar del mismo modo que se cuenta una de ellas o se cuenta un filme. La complejidad temática de una novela no es obstáculo para la jerarquización de los temas. Si hablamos de novela erótica, histórica, de aventura, etc., es porque colocamos como tema principal el eros, el pasado o el riesgo del protagonista, pero al mismo tiempo detectamos la existencia de subtemas que enriquecen el discurso sin distraerlo del tema principal. Lo mismo ocurre en las fantasías, en donde los yoes genéricos son perfectamente diferenciables, y alcanzan la categoría de yo relevante, en cl sentido al que hacíamos referencia con anterioridad.

\section{Sujeto y memoria}

El sujeto construye yoes porque tiene memoria. No memoria de datos puntuales, muy importante por supuesto, porque es una memoria instrumental, sino la evocativa, la que algunos tratadistas actuales como Tulving, Kinsbourne y Ruiz-Vargas denominan memoria episódica, que tiene la característica singular de ser una memoria explícita, es decir, que puede hacerse emerger en referencia concreta al episodio que se actualiza. Es lo que se llama rememorar, evocar. En la evocación, en la rememoración - que puede también provocarse a partir de un hecho actual - pasa como con el fantasear: el sujeto, mediante el yo utilizado en aquel momento, está necesariamente involucrado. Cuando evocamos una situación pasada nos recordamos actuando en ella. Evocar es recordar-se. De nuevo hay que recurrir a la reflexividad, a la disociación como $s i$, en este caso de un yo evocado y un yo evocador, que lo contempla y lo sanciona, de la misma manera que en el ejemplo con que iniciábamos estas conferencias, el «qué idiota fui». Al evocar, el yo y la situación evocados son contemplados como contemplamos un vídeo de aquella situación que rememoramos, pero con el yo de protagonista.

Conviene hacer notar algo hasta ahora relativamente inadvertido, salvo en alusiones muy de través y como de pasada. En la evocación el yo evocado no es exactamente el mismo que el yo que fue en la actuación. Al evocar se modifica el yo de la actuación evocada. Por lo pronto, como decía antes, además de poner orden en lo evocado (orden que o no existía o es distinto al que hubo cuando sucedió), el yo evocado adquiere un protagonismo distinto del que 
tuvo en la situación real. De aquî que la memoria no sea de fiar, no tanto en los datos puntuales (había una mesa a la derecha y dos sillas, en una de las cuales estaba sentado fulano de tal, y cosas de este jaez), sino respecto del valor de la posición del yo en la actuación de entonces.

Con todo lo que entraña de no fiable, gracias a la memoria evocativa de las situaciones que hemos vivido, es decir, de la memoria de nuestras actuaciones, tenemos biografia, una biografía que, como he dicho en otro lugar, siempre tiene, por la razón que acabo de aducir de desplazamiento hacia el protagonismo, un componente de autoengaño, o cuando menos de ficcional. Aun así, gracias a la memoria evocativa - a la serie de evocaciones que hacemos de nuestras situaciones experimentadas - se conserva la continuidad del sujeto en la construcción de yoes tan dispares como lo son todos aquellos con los que actuamos a lo largo de nuestra vida. Jaspers hablaba, como he dicho, de la mismidad («soy siempre el mismo») del sujeto en sus yoes. Significaba con ello la conciencia de que nos reconocemos el mismo pese a recordarnos distintos, y nos sabemos continuadamente el mismo. Schopenhauer habia precisado otros extremos. Para Schopenhauer había dos tipos de recuerdos: uno, del yo de la actuación realizada con anterioridad, lo que hemos llamado el yo y la situación evocados; otro, el del hilo conector de una actuación con otra (la continuidad del yo, de Jaspers). El olvido, pucs, en su opinión, podía ser o de una actuación concreta o del nexo de una y otra. Cuando falla el hilo conector entre una y otra evocación, añadía, esa fisura en la continuidad del sujeto en sus sucesivos yoes ha de subsanarse mediante la falsificación, siempre a nuestro favor. El yo inventado, imaginado para esta conexión de evocaciones, es falso e introduce una distorsión en el decurso biográfico. El sujeto se cree su propio invento. Para Schopenhauer, ése era uno de los caminos por los que se desembocaba en la locura.

De todas formas, de acuerdo con la teoría del sujeto como constructor de yoes, la diferencia entre biografía y autobiografía es sobresaliente, cuando menos en una situacion ideal. El biógrafo, me refiero al biógrafo moderno, parte de uno y otro y otro de los yoes - al modo como lo hizo Painter con Proust, Hayman con Kafka, Ellmann con Joyce, entre otros-, los describe sin más, y, a diferencia del biógrafo antiguo, tipo Bielschowski o Stefan Zweig, elude la definición del biografiado. En efecto, si el sujeto es inaccesible para los otros, que acceden sólo a sus yoes, entonces el sujeto es por principio indefinible y sólo descriptible a partir, claro está, de sus actuaciones observables. Esto vale también para la autobiografía, por cuanto en ésta siempre hay cuando menos una selección de actuaciones, si bien cabe la posibilidad de que se añadan en la descripción yoes imaginados, fantaseados y hasta soñados.

Hasta los profanos tienen actualmente alguna experiencia de la enfermedad de alzheimer, porque se vive más que antes y da lugar a que aparezca en un número considerable de la población. ¿Qué ocurre en esta afección, que a veces se inicia en la sexta década de la vida? Los que viven cerca del paciente 
lo dicen gráficamente refiriéndose a la primera etapa, a los comienzos: no recuerda lo que acaba de hacer (no le es posible la evocación de lo inmediato); sí, de lo que hizo en un pasado relativamente próximo y desde luego mucho antes, incluso en su infancia. Posteriormente, al progresar el proceso disolutivo, no evocará lo que hizo en un pasado próximo; luego, al no reconocer a los hijos no evocará sus yoes de padre; finalmente, no evocará su nombre y no sabe ni siquiera quién es. Llegado a este punto, no es sujeto. Merced a la imposibilidad de evocar las situaciones que vivió, el cnfermo de alzheimer se queda sin autobiografía, olvidado del sujeto que fue, de los yoes que hubo de construir.

Éste es el momento de dar cuenta de un hecho de una importancia decisiva para la economía del sujeto. Me refiero a la asunción de los yoes públicos, privados e íntimos. Asumirlos - sin negarlos, sin interferir fisuras en la continuidad de los yoes - supone saber de sí, de lo que se hizo, se pudo hacer, se quiso hacer y no se pudo. Supone devolver al sujeto su máximo contenido. No trato ahora de una cucstión moral, que no es el caso en este momento, sino de otro orden, el de la autocognición, el de la autoconciencia. A la inversa, tenemos muchos ejemplos de situaciones en las que esta inasunción tiene lugar: el sujeto no es capaz de asumir aquellos yoes reprobables, ridículos, desafortunados, y respecto de la realidad de sí mismo adquiere una notoria limitación. Otras veces las consecuencias revisten caracteres patológicos, como es el caso de los delirantes: no soy homosexual, me aluden injustificadamente serlo; o como en los esquizofrénicos: no soy yo el autor de voces con las que me digo tal y tal cosa, sino otros, vecinos, extraterrestres, los que sean. Por una u otra circunstancia, el sujeto, privado de yoes, se empobrece, cada vez más incapaz de reconocerse en aquellos sectores de sí mismo que, quiera o no, son de él. ¿Que biografía puede ofrecer un sujeto que no se reconoce en su heterogeneidad y que, en su lugar, a base de escotomizarse, se ofrece de «una sola pieza», de una «integridad» y una homogeneidad imposible?

\section{Lugar del sujeto}

¿Cuál es el lugar del sujeto? ¿Se puede hablar de un lugar para el sujeto, como hablamos del lugar en donde acontece la visión, la audición, etc.? A mi modo de ver, sí, porque ser sujeto es hacer yoes constantemente: durante el día, en la realidad o en la fantasía; durante la noche, en el ensueño. Por tanto, ser sujeto es una función que se hace y rehace constantemente y la función es localizable cuando menos en su ámbito nuclear.

El sujeto es un sistema del organismo, como he dicho. Es actividad mental $y$, por tanto, se puede afirmar sin posibilidad de error que es una actividad resultante del funcionamiento del necortex cerebral. Tenemos sobrados motivos para pensar que aunque sin duda interviene la totalidad del cerebro (como en la visión desde la retina y nervios y cintas ópticos, radiaciones de Gratiolet 
y cortex occipital; no hablemos todo lo requerido en la producción del lenguaje), la función de sujeto tiene lugar en las zonas de más elevada jerarquía del sistema nervioso central: el cortex prefrontal. En este lugar no puedo extenderme a este respecto, pero aduciré, sin embargo, algunos hechos sobresalientes. Las lesiones de esta zona del cercbro, por un tumor, antes por la sífilis, por el alzheimer, por la curiosa enfermedad de Pick, dan lugar a un cuadro clínico en el que ocurre una auténtica transformación de lo que en términos de uso común se denomina «modo de ser», que podríamos definir como la componente común, el pattern formalmente básico a todos los yoes de un mismo sujeto. Esta transformación se conoce con el nombre de moria y es una de las formas de manifestación de la demencia. Esta forma de demenciación tiene la singularidad de que no afecta a la memoria - el paciente la conserva en bastante buen estado-, de forma que podemos centrarnos exclusivamente en lo que constituye su núcleo. En la moria el sujeto es incapaz de construir yoes adecuados al contexto y su conducta resulta impertinente, ineducada, grosera, aunque sin conciencia de serlo ${ }^{4}$. Se describió en el siglo pasado, y en la medida en que muchas de estas lesiones, sohre todo las de carácter traumático, son estables, la moria constituye un estado permanente del sistema de producción del sujeto. El paciente muestra: 1) un sistema reducido de producción de yoes, de aquí su «simpleza», su no versatilidad, y 2) un comportamiento ineducado: se ríe extemporáneamente, habla de sus necesidades y las hace en cualquier lugar, dice lo que no se debe decir. Cuando el proceso no es progresivo, como en los traumatismos del cerebro prefrontal, es compatible con rendimientos intelectuales operativos, y el fallo se limita al comportamiento social... El libro de Fuster, The prefrontal Lobe, constituye la mejor revisión del problema que ahora existe... En la psicosis esquizofténica también está comprometido el lóbulo prefrontal y el deterioro que tiene lugar después de años de padecimiento de esta psicosis se traduce en lo que Kraepelin llamó Verblödung, una especial insulsez, también perfectamente compatible con buenos rendimientos mnésticos. En los comienzos de esta psicosis, amigos y familiares que conviven con el enfermo hablan de que «es otro», que «no es el que era». El órgano desde el que se construyen los yoes se perturba en esa función básica de acoplamiento de sus actuaciones a los contextos en los cuales se encuentra. Como dije al principio, algo debe pasar, además, en su sistema del sujeto en orden al control de sus yoes fantaseados cuando algunos de éstos, al alucinar, se le escapan y se le alienan literalmente (se hacen, para él, de otros) y los considera ajenos. En la normalidad e integridad del sistema sujeto/yo se conserva la conciencia de la pertenencia de cuantos yoes, públicos o fantaseados, somos capaces de crear, por disparatados que sean; en el esquizofrénico, no: aquellos que parecen estorbarle son expulsados mediante la alucinación y el delirio,

* «Educado» es una palabra de la misma familia semántica que «adecuado». La íneducación es la transgresión de las reglas de la cortesía, mientras la inadecuación de una conducta lo es de las reglas del contexto en general. 
y al fin el propio sujeto queda vacío de yoes, empobrecido hasta la estupidización.

\section{Lugar del yo}

La pregunta ahora es la siguiente: ¿dónde está el yo?, ¿dónde se hacen los yocs? La respuesta es ésta: el yo es y se hace en el cuerpo, en la superficie corporal (donde pueda ser observado, visto), especialmente en el rostro, pero todo el cuerpo (la postura, la mímica, la palabra) se constituye en instrumento de la expresión del sujeto para una actuación. Lo que el sujeto exige al yo lo hace con el cuerpo. El yo es el conjunto de actuaciones, y toda actuación es corporal: hablar, gesticular, moverse, coger, llorar, gritar, etc. Porque hablar se hace gracias a procesos cerebrales que estudia la neurolingüística, pero la finnal common path de toda forma de hablar es la boca, como último eslabón del instrumento fonador y de ella parten los sonidos articulados que denominamos palabras (de las cuales a veces nos arrepentimos de que hayan salido de ella); gesticulamos con los brazos y el rostro, frente a la opción de haber permanecido quietos. Como señalé anteriormente, esto lo vio $W$. James cuando hablaba del cuerpo y de la ropa como de algo de lo cual el sujeto puede decir que son «suyos» y, al mismo tiempo, los demás reconocerlos como «de él». George Herbert Mead, sin citarlo, sostiene idéntica tesis: «el yo es la acción del sujeto frente a la situación». El sujeto esculpe el yo con el cuerpo, único instrumento para la expresión, y, por tanto, para su patencia ante los otros. Ortega sostuvo una tesis análoga en su ensayo Sobre la expresión fenómeno cósmico (ob. comp. II, 577): «La carne se nos presenta, desde luego, como la exteriorización de algo esencialmente interno... Lo interno de la carne no llega nunca por sí mismo a hacerse externo: es radical, absolutamente interno. Es, por esencia, intimidad... El gesto, la forma de nuestro cuerpo, es la pantomima de nuestra alma. El hombre externo es el actor que representa al hombre interior... El cuerpo humano tiene una función de representar un alma; por eso, mirarlo es más bien interpretarlo. El cuerpo humano es lo que es y, "además", significa lo que él no es: un alma." Para Ortega, como para James, como para Kurt Schneider, el vestido, el adorno son prolongaciones del cuerpo y, por tanto, guardan idéntica relación que el cuerpo con aquello que oculta: el sujeto, o, para continuar con el texto de Ortega, «un alma, espíritu, conciencia, psique... persona, como se prefiera llamar a toda esa porción del hombre que no es espacial». No deja de ser curioso que cuando hacemos a solas lo que habitualmente hacemos para los demás, construir y expresar un yo con los caracteres de yo público, si se nos sorprende, se duda de nuestra cordura; a la inversa, los yoes privados apenas se asemejan a los públicos, y cuando cvocamos, por ejemplo, situaciones de comicidad no reímos del mismo modo (a carcajadas) que si lo hacemos con y para otros, si acaso una mera sonrisa. Los instrumentos para los yocs públicos, privados e íntimos son los 
mismos, pero se usan de modo distinto, en el sentido de que usan del cuerpo de una u otra manera.

¿Qué es, en realidad, lo que se calificó de idiota en el ejemplo [1] con que inicié esta exposición?: lo que se habló y se hizo, csto es, lo que se habló y se hizo con el cuerpo: se pronunciaron determinadas palabras que juzgamos ahora impropias, se hicieron gestos quizá incorrectos, se adoptaron posturas inadecuadas. El responsable fue en última instancia el sujeto; pero si no hubiera exteriorizado aquel yo del que ahora se arrepiente, si ese yo hubiera permanecido meramente imaginado, ise autocalificaría luego de idiota? Evidentemente no, porque el sujeto ha triunfado en la imperiosa necesidad del yo de exteriorizarse. Las actuaciones del sujeto se hacen en forma de un yo que, como instrumento, responde a los propósitos del sujeto; un yo que, si resulta embarazoso o inadecuado, se rehace, como se rehace o corrige una carta, una canción, una sonata que "ha salido mal».

El cuerpo es el lugar en el que y con el que el sujeto representa el yo de la actuación, en donde los que interactuamos con él intuimos la verdad o mendacidad del yo que el sujeto nos ofrece, como lo prueba ese ponernos en guardia ante aquel que al saludarnos nos sonríe de tal manera (con sólo la boca, en una mueca horrenda) que induce a pensar que no se alegra de vernos. Sabemos cómo el cuerpo delata a pesar del esfuerzo del sujeto por hacer con él el yo que quisiera representar hábilmente ante aquel que tiene delante y con el que está en obligada interacción. En esos casos, a pesar de los esfuerzos por hacerse, por ejemplo, simpático o afable, es al sujeto al que "no le sale", como se dice en una feliz expresión coloquial, porque se le escapan componentes connotativos de la antipatía preexistente. «Me sonrió al llegar, pero, aunque pretendiera hacérmelo creer, no se alegró en absoluto al verme»: esto podría ser la descripción de lo que acabo de formular acerca de un yo torpemente construido por el sujeto. El sujeto, en efecto, no siempre es capaz de hacer con su cuerpo el yo adecuado, y en este caso le ocurre lo que al mal actor: representa con notoria torpeza la alegría o la tristeza que debiera sentir y no siente.

Si antes decíamos que cada yo remite al sujeto que lo hace, podemos precisar más: es desde el cuerpo desde donde se nos permite inferir al sujeto que lleva dentro. 